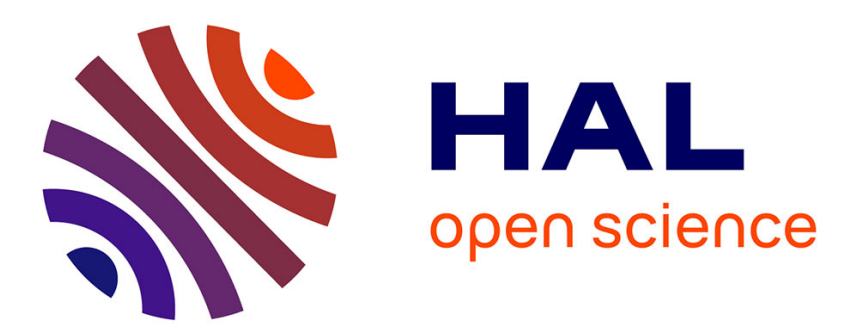

\title{
Organizational agility key factors for dynamic business process management
}

Wafa Triaa, Lilia Gzara, Hervé Verjus

\section{To cite this version:}

Wafa Triaa, Lilia Gzara, Hervé Verjus. Organizational agility key factors for dynamic business process management. 18th IEEE Conference on Business Informatics CBI 2016, Aug 2016, Paris, France. hal01375649

\section{HAL Id: hal-01375649 \\ https://hal.science/hal-01375649}

Submitted on 3 Oct 2016

HAL is a multi-disciplinary open access archive for the deposit and dissemination of scientific research documents, whether they are published or not. The documents may come from teaching and research institutions in France or abroad, or from public or private research centers.
L'archive ouverte pluridisciplinaire HAL, est destinée au dépôt et à la diffusion de documents scientifiques de niveau recherche, publiés ou non, émanant des établissements d'enseignement et de recherche français ou étrangers, des laboratoires publics ou privés. 


\section{Organizational agility key factors for dynamic business process management}

\author{
Wafa Triaa, Lilia Gzara \\ G-SCOP \\ Technology Institute of Grenoble \\ Grenoble, France \\ \{wafa.triaa, lilia.gzara\}@grenoble-inp.fr
}

\author{
Hervé Verjus \\ LISTIC \\ Université Savoie Mont Blanc \\ Annecy, France \\ herve.verjus@univ-smb.fr
}

\begin{abstract}
For several years, Business Process Management (BPM) is recognized as a holistic management approach that promotes business effectiveness and efficiency. Increasingly, corporates find themselves, operating in business environments filled with unpredictable, complex and continuous change. Driven by these dynamic competitive conditions, they look for a dynamic management of their business processes to maintain their processes performance. To be competitive, companies have to respond quickly and nimbly to changing environment. One domain that has dominated the thinking of most managers from few years is organizational agility. It is considered as inescapable feature of today's forward-looking corporates. About $90 \%$ of executives surveyed by the Economist Intelligence Unit believe that organizational agility is critical for business success. Many researchers tried to define and characterize organizational agility according to their context and domain application. The first aim of this paper is to tighten and explicate a conceptualization of organizational agility that clarifies what it is and how it can be reached by proposing a framework that leads to improve organizational agility. The second aim of the current research is to suggest ideas on how to make business processes agile and what are the practices of organizational agility that can be transferred to BPM.
\end{abstract}

Keywords- Master change; Organizational agility; Business Process; Business Process Management

\section{INTRODUCTION}

Processes constitute the core business and create the primary value stream [1]. They arrange interactions between actors and produce a specific product or service for a particular customer. Actually, Business Process Management (BPM) gained considerable attention among academics and practitioners; it addresses the management, transformation and improvement of organizational operations [2]. The goal of BPM is to align the business processes with business objectives and to regularly improve these processes. How well the business processes are organized determines the success of corporates [3]. The technical tool to manage business processes is Business Process Management System (BPMS). BPMSs provide a comprehensive platform to design, deploy, manage the enactment and monitor business processes.

Nowadays, corporates operate in highly turbulent environment having to cope with a frenetic pace of change. Change in business environment and uncertainty have entered management studies and research for a long time [4] How to cope with increasing dynamism and turbulence of work environment has been the most important determinant of firm's success or failure from few decades. These competitive conditions and pressures force corporates to integrate new business value, increase operational efficiency and detect and respond to organizational real time threats. Maintain process organization in practice remains challenging, as it demands high capacity of rapid adaptation.

For several years, many academics and advisers have been searching for successful ways to help corporates to succeed in this rapidly changing, uncertain and turbulent work environment. One from the best and newest way of survival and success of organizations is agility, considered as inescapable feature of today's forward-looking corporates. The goal of agility is to master changes that might occur. Over the last two decades, corporates have focused on improving the agility of their business processes over two dimensions: organizational and technological level. In this paper, we are focused on organizational agility, based on a set of principles and practices used to master change. In references [5] and [6], researchers have argued that organizational agility is one of the most important dynamic resources and capabilities, which allow firms to address rapidly changing business environments. A huge variety of definitions of organizational agility emerged today, heavily influenced by context and application domain. And a lot of work has been done to investigate this topic in different optimization criterions [7], [8], [9], [10], leading to develop many different solutions and methods [11], [12], [13], [14], [15], [16].

Yet, organizational agility is not sufficiently taken into consideration while managing business processes. For several years, most corporates have automated their processes due to business process management technologies [17]. Nevertheless, to be competitive, corporates have to go beyond automating their processes, by making them more agile. Under continuous changing work environment, organizations must be able to modify their business processes without interrupting their execution. Thus, the ease of change and immediate implementation of them are one of the most tangible benefits of BPM systems. To make these processes more adaptable, we suggest integrating practices of organizational agility to BPMS. The aim is to get an agile BPMS that goes beyond the classic features of actual BPMS. 
Considering this scope, an attempt has been made in this paper to study organizational agility in order to apply it on BPMS. This study is based on the review of literature available on the concept of agility in general and more focused on organizational agility.

The rest of our paper is organized as follows. In section 2 , we give a literature review, firstly along with agility and then with organizational agility. In section 3 we will present a framework of organizational agility. In section 4 we will transfer the best practices and principles of the proposed framework of organizational agility over the BPMS. Finally, in section 5 we will conclude this paper.

\section{LITERATURE REVIEW}

\section{A. Agility}

In this section, we explore a variety of agility's definitions. Actually, agility is the most important and relevant success factor for enterprises in today's competitive and fast-changing environment. This was actually affirmed by various researchers (e.g. [7], [4], [18] and [19]). The concept of agility was developed in the context of agile manufacturing [20]. It was introduced as reaction to business environment changes and exploiting them as opportunities. In [7], the authors defined agility abilities to deal with turbulence and capture the advantageous side of the business. Moreover in [21], the authors considered the main driving force behind agility is change and represented this change mainly in customer needs, competitive measures, market, technology, and social components. While in [22], the authors argued that the concept of quickness and therefore speed is at the heart of agility. Although in [23], the authors considered that a successful company must acquire the capability to achieve and explore the competitive advantage in synergy and that agility should not be equated just with the speed of response to change. They suggested that agility is the successful exploration of competitive principles (speed, flexibility, innovation, quality and profitability) through the integration of reconfigurable resources and best practices in an environment with rich knowledge for providing adequate product of services in the variable market environment. Furthermore in [24], the authors defined agility as a continual readiness of an organization to rapidly or inherently create change, proactively or reactively embrace change and learn from change while contributing to perceive customer value, through its collective components and relationships with its environment. Some researchers [25], suggested that an agile response produces high quality, high performance and customer configured goods and services. Though, Sull, in [26], suggested that agility is the capacity to identify, capture, and exploit opportunities more quickly than rivals do. While in [27], Tallon and his colleague proposed that agility is the ability to detect and respond to opportunities and threats in the environment with ease, speed, and dexterity. Moreover, researchers in [22] considered that being agile means perforce having the ability to sense highly uncertain external and internal changes, and responds to them accurately based on innovation of the internal operational processes, involving the customer in exploration activities while leveraging the capabilities of partners in the business network. Agility is a firm's ability to adapt continuously to a complex, turbulent and uncertain environment as proposed by [28], [29]. And it is also considered as the capacity to act and transform the change to opportunity thanks to broad capacities of anticipation, innovation and learning, according to [30]; [29].

Despite the huge amount of the proposed definitions of agility concept, none of them are opposed or contradictory to each other. The handling of change as fundamental prerequisite for agility is confirmed in the literature by all researchers, who considered creation of change, proaction in advance of change, reaction to change, and learning from change as components of agility.

Agility is a complex concept analyzed across enterprise organization, strategic management, and technology [29] [22]. Several research works address enterprise's agility improvement according to two levels: organizational and technological. In this paper we are focused on organizational agility. In the next section, we will give a literature review among with organizational agility.

\section{B. Organizational agility}

The concept of organizational agility was identified by four researchers at the University of Lehigh [28] [31] who had been requested by the American Congress to write a circumstantial report on the strategy of industrial firms in the 21 st century [18]. From that period onward, organizational agility has been considered as primordial factor for firms' survival and competitiveness [18], [32] [33]. Several researchers tried to define the concept of organizational agility according to their domain application and context. They proposed different conceptual models to specify the organizational agility's characteristics. The review of some of these propositions was made below in order to identify the main dimensions, characteristics and attributes of an agile organization.

One of the most well-known conceptualization is given by [28] who developed four main dimensions of organizational agility in order to master change and stay competitive. His work based on 1) enriching the customer by delivering value and solutions rather than products, 2) cooperating to enhance competitiveness, to accelerate the response and optimize the used resources, 3) organizing to master changes by having a rapid reconfiguration of the human and physical resources and lastly 4) leveraging the impact of people and information with a continuous work force education and organizational training. He suggested that to improve organizational agility, corporates have to take profit from their human resources and establish cooperative structure, decentralization and employee empowerment, culture of innovation and continuous learning. Whereas in [34], the authors divided agility capabilities into four main dimensions: 1) product-related change capabilities, 2) change competency within operations, 3) internal and external cooperation, and 4) people, knowledge, and creativity. Moreover in [35], the authors suggested four categories of agile practices: 1) enriching customers, 2) mastering change, 3) cooperating to 
compete, and 4) leveraging resources, especially human resources. Besides in [33], the author defined four agility capabilities: responsiveness, competency, flexibility, and quickness and he suggested four agility enablers: 1) collaborative relationships, 2) process integration, 3) information integration, and 4) customer/marketing sensitivity. Furthermore in [18], based on the proposed models, Charbonnier-Voirin defined the essential characteristics of organizational agility which are: agile drivers, agile capabilities and agile practices. He defined the agile drivers to set up and ensure the success of agile practices and subsequently those practices which are supported by the agile drivers ensure the development of agile capabilities. In fact, agile drivers represent the agile corporate's infrastructure which is made up of reconfigurable levers which can be deployed when changes occur. These reconfigurable drivers are: the corporate's organization and structure, its processes, technology and human resources. They are conceived to ensure the success of agile practices. Adding to that, corporate's infrastructure is made up of stable levers too, which ensure the continuity of organization. These stable levers are vision and value which have to be shared and the use of common performance metrics [36]. Reconfigurable and stable levers called also drivers boost the improvement and control of agile practices which represent the most operational level of organizational agility as it was affirmed in the literature. Besides agile practices known also as agile attributes are classified into four main categories: 1) practices directed towards mastering change, giving the teams the ability to develop their reactivity and being able to work in real time, 2) practices promoting the value of human resources, helping the employees to adopt the necessary autonomy and responsibility for dealing rapidly and efficiently with the many unpredictable situations that might occur, 3) cooperative practices, inside and outside corporates are essential in order to reduce response times and increase their potential for innovation and finally 4) practices to create value for customers, which are essentially focused on customers satisfaction. These practices supported by the agile drivers ensure the development of agile capabilities. Indeed, agile capabilities are essential strategic abilities which enable the firm to respond to change and establish its competitive bases. Various terms are used to name these capabilities: responsiveness, anticipation, adaptation or reconfiguration, efficiency, flexibility, quickness, innovation, knowledge management and learning. They are gathered into three important capabilities: 1) the organization's aptitude to mobilize a rapid response to change which is based on reactive flexibility and the optimization of existing resources. 2) The aptitude to read the market enabling corporates to explore and detect potential or emerging developments through its watch capabilities and 3) the aptitude to integrate organizational learning corresponds in particular to the ability to adjust human capabilities and qualitatively align them with the organization's strategic perspectives.

Moreover, various research works were conducted to measure organizational agility. One from these propositions was done by [33]; these authors utilized fuzzy logic as a measurement tool of organizational agility. Their model is connected to the concepts of agile manufacturing with agile enablers, capabilities and drivers. It is composed of two essential parts. The objective of the first part is to collect and analyze changes (considered as agility's drivers) in the business environment, in order to adjust their processes and make the appropriate responses. The second part is used to evaluate agility's capabilities by using a fuzzy agility index (FAI), which is calculated as a weighted average of performance rating of various agility attributes and their relative importance. Furthermore, in [4] the authors mentioned various steps to implement agility in organizations. Firstly, it is required to define and determine the nature of the organization's work environment. Then, an assessment and evaluation of the considered organization's agility is done in order to define the plan of action due to a set of viable tools used to attain agility, based on the agile organization's capabilities. A similar proposition for organizational agility evaluation was proposed in [40]. The authors defined the following steps to improve organization's agility. Firstly, the market trends need to be evaluated. Then, the strategic objectives are analyzed. Finally, according to this analysis, the suitable capabilities are selected and used to increase organizational agility. Another proposition was done by [25], which presents a direct, adaptive, holistic and knowledge based framework. In order to assess organizational agility, various quantitatively agility parameters were regrouped into four main infrastructures: product, market, people and information infrastructure. The key idea of the proposed framework is to combine all the infrastructures and their corresponding operational parameters to determine the overall agility using fuzzy IF-THEN rules. Moreover, the work of [23] was used again with [10] to analyze and conceptualize the organizational agility concept. The defined agility characteristics were used to identify the most appropriate enablers of organizational agility using the quality function deployment (QFD) methodology and especially the house of quality (HOQ).

\section{Synthesis}

The focus of the current literature, which has examined the concept of agility, has focused more exclusively on the characteristics, parameters and factors of organizational agility. We will give a summary in the table below (Table I) of the most agreed upon concepts of organizational agility. This table presents the correlations between these concepts according to the elaborated review of the literature. In other words, every time, we couple two concepts and check if they are mentioned together in the same reference and so we count the number of correlations of each couple according to our 16 references.

For example, facilitates 'cooperation' and teamwork will lead especially either to 'enrich the customer' due to a rapid detection of his expectations and proactive resolution of his problems or to create value to enterprise due to 'continuous learning'. Thus, cooperation is a crucial concept of organizational agility in order to 'reduce response time' and increase the enterprise's potential for innovation. 
Accordingly, continuous learning, enriching the customer and rapidity are the most correlated concepts to cooperative practices as it is illustrated in Table I. Moreover, 'empowerment' and continuous change leads to enrich the enterprise's repertoire of skills through the creation of conditions for 'continuous learning'. Furthermore, one subcomponent of 'empowerment' is 'decentralization' and its determination of decision making authority. Therefore, continuous learning, autonomy and decentralized decision making are the most interrelated concepts to empowerment. In addition, reconfiguration and flexibility are crucial concepts to accelerate adaptation to change which is illustrated within the correlation between these concepts and rapidity in Table I.

In the literature some authors used responsiveness to describe the ability to react to a change in the environment in a timely manner. Thus, a rapid incorrect action is not responsive, and responsiveness can be measured by the relative numbers of opportunities identified and exploited [41]. In our research we want to distinguish time, quality and cost of the response to change that is why we used rapidity rather than responsiveness.

In the next section we will depict the framework of organizational agility.

\section{ORGANIZATIONAL AGILITY FRAMEWORK}

The framework presented here is based on an integration of perspectives from the elaborated literature review as well as our personal perspectives. Our preliminary conceptualization is based on the agility's definition, where identifying and responding to change are its critical elements. In order to explicate the characteristics of organizational agility, we further decomposed its definition to examine the types of changes that enterprises must be able to sense, how they could be sensed and the types of responses that enterprises have to develop. A summary of this decomposition appears in Fig. 1. From this, we are able to construct a preliminary profile of organizational agility. Upon sensing environmental change, there are two types of responses that an enterprise can make according to the type of change. Indeed, the appropriate response to exploited change leads to develop a reactive response while the anticipation of the suited response to explored change leads to develop a proactive response. Besides, the anticipation of change leads to reduce its toll and giving the organization the ability to have a continuous and rapid adaptation of their business processes.

Table I. Synthesis on organizational agility concepts

\begin{tabular}{|c|c|c|c|c|c|c|c|c|c|c|c|c|c|c|c|}
\hline & 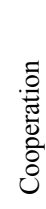 & 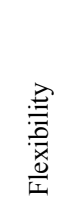 & 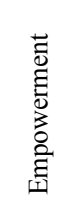 & 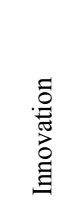 & 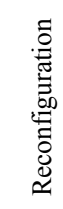 & 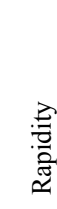 & 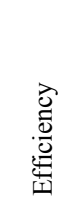 & 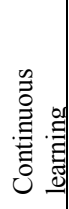 & 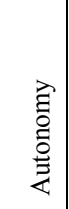 & 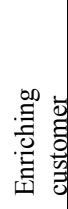 & 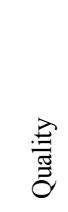 & 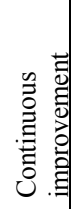 & 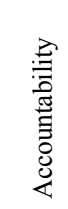 & 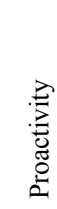 & 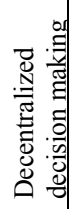 \\
\hline Cooperation & & 3 & 3 & 1 & 3 & 4 & 1 & 5 & 1 & 6 & 2 & 2 & 3 & 3 & 3 \\
\hline Flexibility & & & 2 & 1 & 4 & 6 & 2 & 4 & 1 & 2 & 4 & 2 & 2 & 4 & 3 \\
\hline Empowerment & & & & 1 & 0 & 1 & 1 & 2 & 2 & 1 & 1 & 1 & 0 & 0 & 2 \\
\hline Innovation & & & & & 0 & 1 & 0 & 1 & 1 & 3 & 1 & 1 & 0 & 3 & 0 \\
\hline Reconfiguration & & & & & & 4 & 1 & 2 & 0 & 4 & 0 & 1 & 0 & 1 & 1 \\
\hline Rapidity & & & & & & & 1 & 2 & 0 & 6 & 3 & 2 & 3 & 5 & 2 \\
\hline Efficiency & & & & & & & & 2 & 0 & 2 & 1 & 1 & 0 & 1 & 2 \\
\hline Continuous learning & & & & & & & & & 1 & 3 & 1 & 2 & 0 & 2 & 1 \\
\hline Autonomy & & & & & & & & & & 0 & 0 & 0 & 3 & 1 & 4 \\
\hline Enriching customer & & & & & & & & & & & 4 & 1 & 1 & 4 & 2 \\
\hline Quality & & & & & & & & & & & & 1 & 1 & 3 & 1 \\
\hline Continuous improvement & & & & & & & & & & & & & 0 & 1 & 3 \\
\hline Accountability & & & & & & & & & & & & & & 1 & 1 \\
\hline Proactivity & & & & & & & & & & & & & & & 1 \\
\hline $\begin{array}{l}\text { Decentralized decision } \\
\text { making }\end{array}$ & & & & & & & & & & & & & & & \\
\hline
\end{tabular}


Otherwise, regarding the unlimited number of changes, the probability to fail (e.g. don't select the appropriate skills, appropriate tasks, appropriate allocation...) while developing response to an emergent situation is more important. When new threats or opportunities emerge on the periphery of corporate's usual business environment, they fail to notice them or misinterpret their emergence. Thus, the most basic sub-component of mastering change is to analyze and understand work environment which we call "Intimate understanding of work environment". We will depict in the section below how organizations could intimately understand their internal and external work environment.

\section{A. Intimate understanding of work environment}

Change, the main driver of agility, can happen in the internal or external work environment. Recall that relevant forces of external changes include competitors' actions, consumer preference changes, economic shifts, technological advancements [42]. While internal changes are directed by leadership style, the organization's mission, or its culture. This change has to be normally exploited and/or explored in timely manner. In [38], March defined exploitation as the use and development of things already known through refinement and extension of existing competencies, technologies, and knowledge. And he suggested that exploration is an organizational experimentation with new alternatives and pursuit of knowledge about currently unknown opportunities for competitive action. So, to enhance these capacities, an intimate understanding of internal and external work environment leads to improve corporate's awareness of sudden and gradual modifications and unknown opportunities.

Intimate understanding of external work environment is directed by the market and the customers. Interacting with customers and suppliers is based on organizational agility enablers mentioned in the previous section: which are collaboration, communication and cooperation. These practices will enable knowledge production and knowledge sharing in a timely manner and that firms are better integrated with external customers, suppliers, and partners. To have continuous interaction and real time accessible information, corporates have to use technology to transcend the barriers of time and space and increase the accessibility of the information. The use of technology will lead to gather information about competitors, find ways to effectively reach customers' expectations and increase the accessibility of information. Adding to that, to maintain ongoing awareness of information security to support organizational management decisions, these enablers have to be supported with the two other concepts of organizational agility, continuous monitoring and continuous learning. They create a continuous feedback loop of risk and mitigation.

Moreover, the intimate understanding of internal work environment refers to understand the special expectations and difficulties involved in workplace which threatened process's performance and lead to minimize the cost and elapsed time of carried out action. Actually, process's organization is poorly equipped to prevent or withstand attacks, the key difficulty is to detect intrinsic changes that are not necessarily directly observed and that are measured together with other types of perturbations. Even sudden or gradual modifications, which affect the process without causing it to stop, must be analyzed and controlled to prevent the subsequent occurrence of more complex situations. Likewise external work environment, intimate understanding of internal work environment is based on the organizational agility practices listed above: collaboration, communication, cooperation, continuous monitoring and continuous learning.

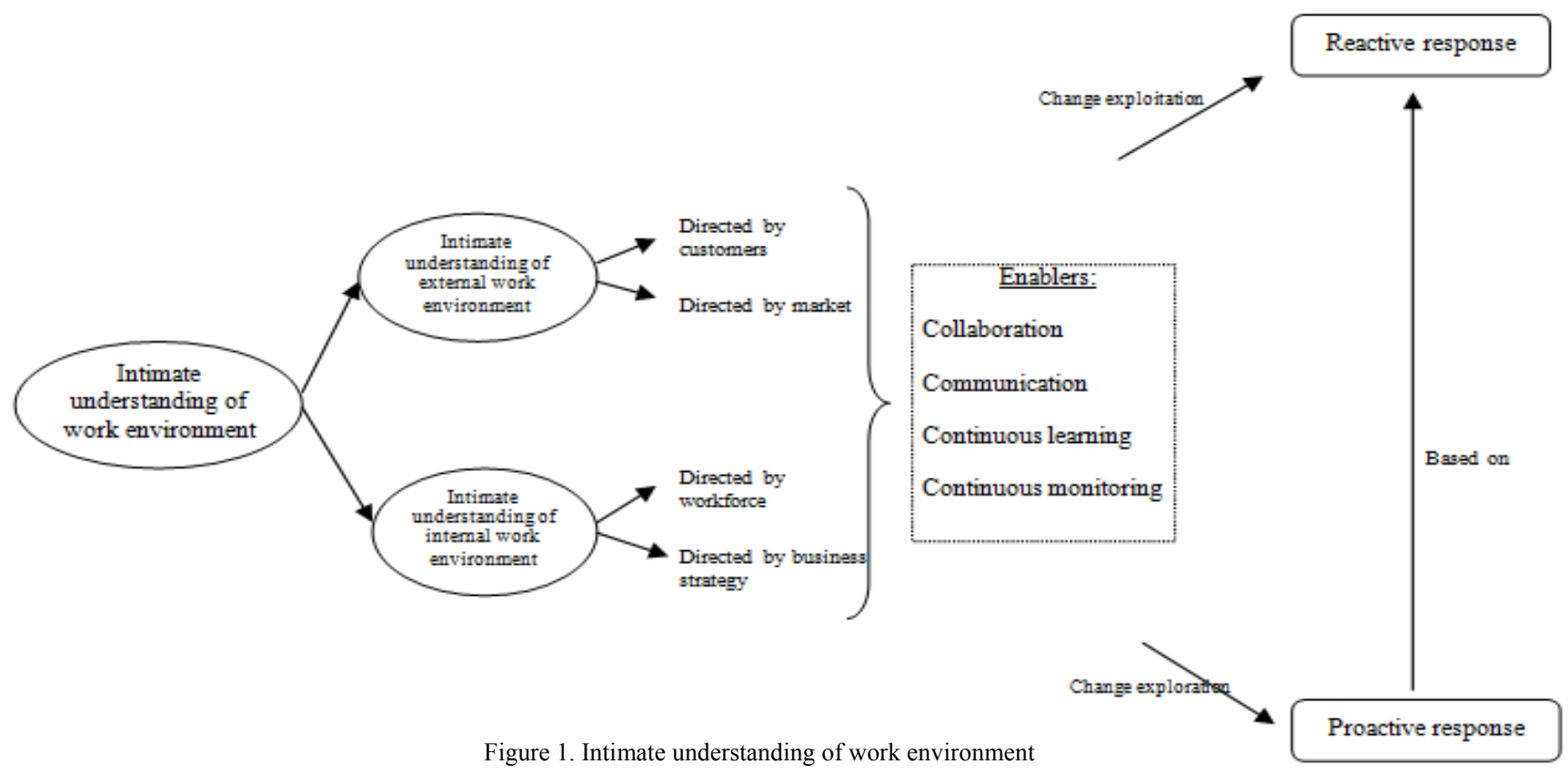


Upon sensing environmental change, two types of responses can be developed. The first responses classification encompasses reactive response, such as adjusting product features, change resources allocation, while the second responses classification encompasses proactive response, such as launching a new product, targeting a new customer segment, assessing and extending the enterprise's repertoire of skills etc. In the section below, we will depict how reactive and proactive responses are developed.

\section{B. Reactive response enablers}

Reactivity is a phenomenon that occurs when performance is altered in order to react in response to what occurred. The central theme of this section is the decomposition of reactive response into three factors: velocity, effectiveness and efficiency as illustrated in Fig. 2. These factors have to be aligned to improve the reactivity of the response. In other words, the three enabling factors of the reactive response are in sync with each other. Firstly, velocity represents the duration of the response's implementation from the moment of change detection until the adaptation to the new situation. In the framework, we used velocity rather than rapidity since rapidity is a relativistic velocity. Returning to Fig. 2, we can infer that response's velocity depends on several concepts. Thereby, to reduce the velocity of the response, corporates need to eliminate all sources of wasting time and factors that can delay the adaptation to the new situation. These sources can be caused by lack of resources adaptation and/or lack of flexibility of the process's model. On the one hand, longer period of resources adaptation can be caused by a misunderstanding of strategic objectives and customer's expectations. Thus, working with customers, incremental releases and rapid feedback are some of the ploys used to mitigate the risk of demand uncertainty and to better understand business objectives. Thus, it is important to have rapid distribution of information to make it easily accessible within practices of collaboration, cooperation and communication inner and outer the organization. Furthermore, centralized decision making are considered as too inaccurate and too weak to absorb successfully and marketable the required complexity of the organizational challenges. They lead to delay resources adaptation. In fact, the principal defect of centralized organizational structures is their tendency to reduce managerial expertise on the shoulder of a small and uplifted group of people. The lack of information dissemination, lack of collective empowerment, mind setting and lack of accountability, lead to have stable and secure situations of work. Thus, in such situation, employees rely on their existing knowledge and acquired interpretations. However, the increased need for orientation in times of crisis or dramatic change requires more open people to new information. It becomes necessary for everyone in the organization to understand not only the process in which they work, but also their own specific task, along with the impact of their work on other aspects of business. Another important contingent variable that supports rapid resources adaptation is the use of multi-skilled employees in order to develop a flexible workforce. Instead of performing exactly one task, flexible employees are able to perform more tasks. The availability of these employees adds more flexibility to the process. They are able to fill in absent employees and work various tasks. It provides the ability to schedule and arrange resources readily to best suit the scalable needs of business processes. On the other hand, process's structure has to be generic and flexible too. In other words, processes structure definition has to be open in order to support flexible/temporal dependencies between tasks. This definition will be directed by the context. Since, the rigid configuration of the implemented process may lead to delay the adaptation and redefinition of existing processes. Moreover, an adverse selection and mobilization of skills and tasks and an inadequate coordination between tasks and resources or tasks and processes carried out by different individuals, work groups, departments, business units across various business entities or across different hierarchical levels provoke cross-functional conflicts. Thus, to accelerate the implementation of the response, dynamic coordination is needed for an effective realization in turbulent environment.

While facing change, corporates should have a compromise between speed and quality of the developed response, which requires informed decision making based on reliable, understandable, and timely environment-related information tailored to user needs. The second enabling factor of reactive response is effectiveness. This effectiveness defines the ability to achieve strategic goals of processes. It relies on the ratio of the achieved results to the desired target criterion. To improve this effectiveness, the quality of the results obtained by executing the considered processes must be improved. Improving the quality of processes involves improving the quality of used tasks which depends on the quality of its corresponding skills. That's why; the allocated skills must be the most effective ones. The skills allocation must be based on a first-time right choice of performing skills. Another important key factor to enhance effectiveness is to have motivated employees. One from the best ways to motivate the employees is teamwork. Furthermore, continuous monitoring of processes and performance evaluation concepts are essential to ensure the dynamic improvement of the response development. Continuous monitoring helps to identify threats quickly and with precision. This allows the better management of processes and respect of business expectations. And performance measurement is crucial for identifying and tracking progress against organizational goals and identifying opportunities for improvement.

Yet, agile organization must have a deep reflex on its financial performance and how it can be improved. In other words, face to change, a rapid, effective and with minimal cost the adaptation should be done, which is called response efficiency, one from the most important Lean concept. So the last core enabling factor of a reactive response is efficiency. Identify and eliminate waste (non-value added tasks), by flowing the product at the pull of the customer are the main principles of Lean. Thus, work under pull flow, eliminating waste and optimizing resources are the main key factors to improve response's efficiency. 


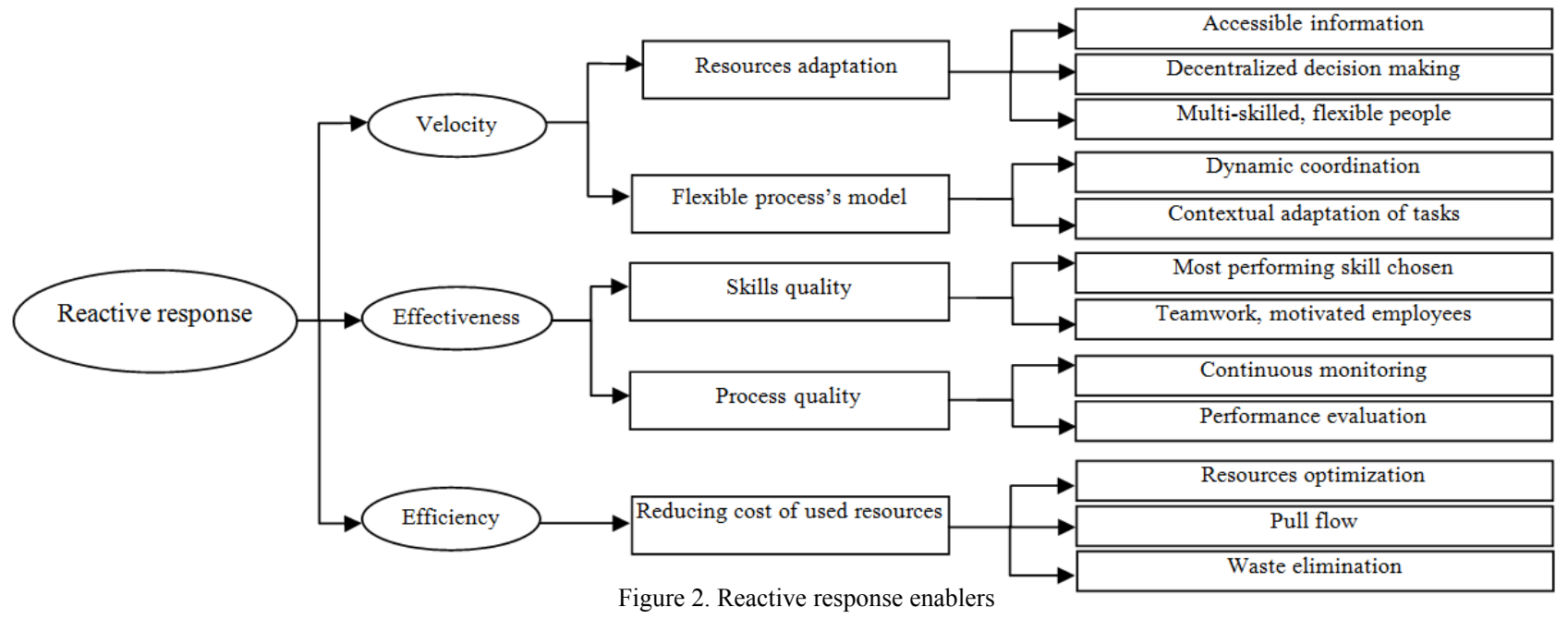

So to capitalize, reactive response is based on velocity, effectiveness and efficiency of response implementation as it is illustrated in Fig. 2. And the corresponding attributes of each factor are depicted in Fig. 2 too.

\section{Proactive response enablers}

The same methodology is used here to conceptualize the proactive response. Proactivity is the initiated activity using anticipation of what could occur and the defined decision of what to do to create the desired results. Thus, within organization proactive response is decomposed into two factors: organizational anticipation and innovation which refers to the ability to do new things and the ability to do old things in new ways. These factors have to be in sync between each other and aligned with the factors of the reactive response too.

Otherwise, it is conceivable for corporates to have the capabilities to sense the correct opportunities to pursue. Proactive response is developed either to recognize potential changes before competitors do, to remain vigilant and curious about signals and also have the courage to act when these signals are still ambiguous. It starts by an anticipation of change. Corporates are able to integrate the change into their business strategy effectively using foresight and anticipation which means expecting, being aware of an evolution in advance, in order to have an efficient speed and change management. Sources of threat and opportunity are various. Sometimes, they originate in new customer's requirement not explained. In this case, corporates have to exploit them as an opportunity. And they can also originate in an internal evolution (delay, departure of personnel, supplier problems...), where corporates have to be vigilant of these modifications that can affect their process's performance.

Change's anticipation is followed by developing a reactive response based on innovation culture. This innovation leads either to create value for customers or for corporates. Customers' value creation is reflected in a proactive resolution of their problems while corporates value creation is observed in the development of new skills, enrichment of tasks or implementation of a remedial action due to the continuous improvement.

The ability to rapidly develop new skills is especially critical in environments characterized by rapid innovation and change. To facilitate skills development, organizations have to scan their work environment and intimately understand its ever changing characteristic to anticipate future skills requirement easily. Moreover, task enrichment will provide many opportunities for employee's development. It gives them opportunities to participate in how their assigned task gets done and it will increase the sense of personal responsibility and leads to creativity. Adding to that, continuous improvements are necessary and that both the organizational culture and formal structures should encourage it. It is known as Kaizen, long-term approach systematically used to incrementally improve efficiency and quality.

So to capitalize, proactive response is based on innovation and organizational anticipation capacities as it is illustrated in Fig. 3. And the corresponding attribute of each factor are depicted in the same figure.

To synthetize, organizational agility develops corporate's awareness of its internal and external environmental change; and develops its understanding of their business needs to evolve its aims in response to, or in anticipation of, environmental change.

Organizational process adaptation is not a one-time or even periodic task; it is a continuous process in this actual turbulent work environment. To maintain this adaptation and have a dynamic process management, it is important to establish practices that foster an agile culture. In the next section, we will give some ideas to make BPMS agile based on practices of the presented framework in section III. These practices enable BPMS to support process's agility.

\section{TRANSFER OF AGILITY PRINCIPLES TO BPMS}

As the framework suggests, multiple operating and strategic concepts support organizational agility. Creating and maintaining them depends on the context in which agility is needed. Refers back to the definition, agility is 


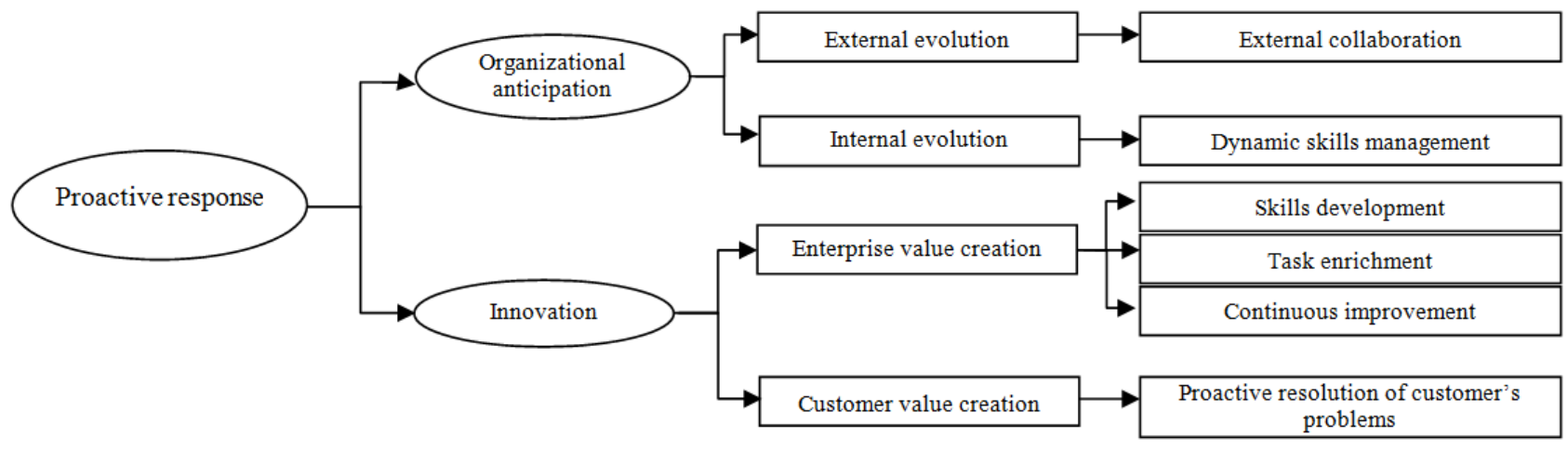

Figure 3. Proactive response enablers.

needed when enterprises are affected by environmental changes, which are reflective of turbulent and dynamic environments. More the work environment become increasingly turbulent more agility is needed. Thus, actual BPMS as they play an important role in solving multiple process-related issues through automation, collaboration and visibility have to support agility. These processes have to be continuously adapted and altered to constantly reach business needs, the root of their definition. Currently, BPMS support the entire BPM lifecycle, from identifying processes to analyzing, redesigning, implementing and monitoring these processes. They allow the management of business processes that are representative of the enterprise's activities independently of the used resources. Moreover, striking the balance between business management, evolved in a complex, turbulent and uncertain environment, and IT aspects, characterized by deterministic view, is crucial for the success of BPMS implementation. Thus, BPMS have to go beyond their classic features and incorporate the following to support business process's agility:

- Scalable resources reconfiguration: according to the framework, dynamic coordination and first time right chosen of performing skills are crucial concepts to continuously support the continuous adaptation of resources allocation. Indeed, resources are important assets in successful process's implementation. They have to be aligned with business needs by transitioning easily and rapidly from one resources allocation to another in order to ensure process robustness. However, current BPMS do not feature the means to self-adaptive resource allocation process execution which means the ability of a system to detect and recover from potential problems and continue to function smoothly. Thus, they need to be aligned with resources management and continuously control the availability and feasibility of the current running processes. Furthermore, in order to avoid over- and underprovisioning, BPMS should be able to lease and release resources during runtime. Hence, they have to support the automatic adaptation between different resources allocation without changing the processes themselves.
- Accessible information: The information used as a basis for decision-making is threatened of becoming outdated and distorted. The key requirement for the success of process management is that the information is and stays valid. The accession of the required information in real time is a crucial concept of the framework. Otherwise, actual BPMS enable team communication and problem solving through task sharing, email integration, instant messaging. But they don't support the customization of information distribution during run time. Thus, they have to support collaboration, rapid, efficient and continuous information access and exchange, and global connectivity while processes are executed. This feature leads to help decision-makers in order to have continuous access to relevant, valid, customized and real-time information, on which they base their decisions. Moreover, they will enable process participants to make sense out of what would otherwise overwhelm their work.

- Intelligent analytics \& decision management: Actual BPM resources need to have the capacity to understand, analyze and even predict what is going to happen in the general business environment (this capacity is called organizational anticipation of the proactive response as depicted in Fig. 3). Analysis capacity will enable the conversion of data into useful and relevant information that will be distributed to the right resource at the right time, so that they can make appropriate and well-founded decisions. Depth analysis related to internal processes leads to identify operational deficiencies such as fulfillment problems. Moreover, it is important to control operational decision making. By increasing the precision of operational decisions within processes leads to have a better assessment of risk. Continuous learning and understanding decisions lead to make processes management smarter and ensure robustness.

- Contextual process management: Contexts change over time. Thus, processes require continuous adaptation to the given context. Current BPMS do not account for a broader variety of business 
contexts of their processes. They are focused mainly on clear structured processes that require improvement, standardization, or automation. Therefore, another lever to make BPMS more agile is to take into consideration the context while managing business processes which is reached due to contextual adaptation of tasks as depicted in Fig. 2 to improve process's model flexibility.

These features support process's agility which enables processes to be adjusted quickly in order to meet changing environmental conditions.

\section{CONCLUSION}

The objective of our research is to contribute to the understanding of agility and organizational agility. This is an important issue, since agility is a fundamental feature of a business processes management in terms of continuous adaptation and value creation. After conducting a literature review on agility, we identified aspects that are viable to understand the organizational agility. Based on this research on enterprise's agility and organizational agility, we propose a framework summarizing properties of organizational agility. By juxtaposing the two critical elements of agility, this paper illustrates the enabling characteristics of organizational agility. Each identified concept is needed but not sufficient condition for organizational agility.

Moreover, we claim that BPM has to support, enact and integrate organizational agility in order to dynamically manage business processes. Under uncertain conditions, it is important to stress continuing adaptation, rapid innovation and learning in order to support business processes. Process's management has to be creative about how to manage and evolve the given business processes. Integrating organizational agility properties with BPMS is a powerful way to adapt to change.

In this viewpoint article, we argue that BPMS should be aligned with resources management, to easily and rapidly transition from one resources allocation to another. It should support collaboration, accessing and exchange of customized information, decision management and contextual process management.

Currently, our future research striving towards the development of a BPMS that supports agility of business processes. Particularly, our work will focus on the runtime and how to help actors to get the customized and real time information, used as a basis for their decision-making.

\section{REFERENCES}

[1] C. F. Strnadl, "ALIGNING BUSINESS AND IT : THE PROCESSDRIVEN," vol. 0530, no. April, 2016.

[2] M. Shitkova, J. Holler, T. Heide, N. Clever, and J. Becker, "Towards Usability Guidelines for Mobile Websites and Applications," pp. 1603-1617, 2015.

[3] H. Smith, "Business Process Management: The Third Wave: Business Process Modelling Language ( BPML ) and Pi-Calculus Foundations The Theoretical Foundations of the Third Wave of Process Management," 2003.

[4] B. Sherehiy, W. Karwowski, and J. K. Layer, "A review of enterprise agility: Concepts, frameworks, and attributes," Int. J. Ind. Ergon., vol. 37, pp. 445-460, 2007.
[5] P. Hutterer, "Dynamic Capabilities," Dyn. Capab. und Innov., pp. $181-244,2013$

[6] C. O. F. Irms and V. Grover, "S Pecial I Ssue S Haping a Gility Through D Igital O Ptions: R Econceptualizing the R Ole of I Nformation T Echnology in," MIS Q., vol. 27, no. 2, pp. 237-263, 2003

[7] H. Sharifi and Z. Zhang, "Methodology for achieving agility in manufacturing organisations: an introduction," Int. J. Prod. Econ. vol. 62, pp. 7-22, 1999.

[8] G. Suganya and S. a. Sahaya Arul Mary, "Progression towards agility: A comprehensive survey," 2010 2nd Int. Conf. Comput. Commun. Netw. Technol. ICCCNT 2010, 2010.

[9] Y. Gong and M. Janssen, "(ACM-0040) [S4] Measuring process flexibility and agility," Proc. 4th Int. Conf. Theory Pract. Electron. Gov. - ICEGOV'10, no. February 2016, p. 173, 2010.

[10] E. Bottani, “A fuzzy QFD approach to achieve agility,” Int. J. Prod. Econ., vol. 119, pp. 380-391, 2009.

[11] Schwaber, K. Agile Project Management with Scrum. Microsoft Press, Redmond, WA. 2004

[12] Jeffries, R., Anderson, A, and Hendrickson, Extreme Programming Installed, Boston, MA: Addison-Wesley, 2001.

[13] Stapleton, J, DSDM-Dynamic systems development method. Boston, MA: Addison Wesley, 1997.

[14] Palmer, S,R., \& Felsing, J, M., A practical guide to feature-driven development. Upper Saddle River, NJ; Prentice-Hall Inc, 2002.

[15] Ladas, C, Scrumban-Essays on Kanban systems for lean software development. Modus Cooperandi Press, 2009.

[16] S. Saidani, O.; Nurcan, "Towards Context Aware Business Process Modelling," in The 8th Workshop on Business Process Modelling, Development, and Support, 2007.

[17] V. Shankararaman and S. Gottipati, "A Framework for Embedding Analytics in a Business Process," 2015 IEEE 17th Conf. Bus. Informatics, pp. 49-54, 2015.

[18] A. Charbonnier-Voirin, "The development and partial testing of the psychometric properties of a measurement scale of organizational agility.,"M@n@gement, vol.14,no.2,pp.119-156, 2011.

[19] M. K. Moshki, H. Teimouri, and R. Ansari, "A survey on the level of Information Technology Acceptance and proposition of a Comprehensive model (The Case of Nir Pars Company)," Int. J. Acad. Res. Bus. Soc. Sci., vol. 3, no. 3, pp. 214-228, 2013.

[20] Upton, D, M., The management of manufactoring flexibility, California Management Review, Winter, 72-89, 1994.

[21] C.-T. Lin, H. Chiu, and Y.-H. Tseng, "Agility evaluation using fuzzy logic,” Int. J. Prod. Econ., vol. 101, pp. 353-368, 2006.

[22] M. Van Oosterhout, E. Waarts, and R. Axelsson, "Business Agility :," vol. 44, pp. 52-69, 2007.

[23] Y. Y. Yusuf, M. Sarhadi, and a. Gunasekaran, "Agile manufacturing: the drivers, concepts and attributes," Int. J. Prod. Econ., vol. 62, pp. 33-43, 1999.

[24] K. Conboy, "Agility from first principles: Reconstructing the concept of agility in information systems development," Inf. Syst. Res., vol. 20, no. May 2015, pp. 329-354, 2009.

[25] N. C. Tsourveloudis and K. P. Valavanis, "On the measurement of enterprise agility," J. Intell. Robot. Syst. Theory Appl., vol. 33, pp. 329-342, 2002

[26] Sull.D, Competing through organizational agility, McKinsey Quarterly, 2009

[27] P. P. Tallon and A. Pinsonneault, "Competing Perspectives on the Link Between Strategic Information Technology Alignment and Organizational Agility: Insights from a Mediation Model," MIS Q., vol. 35 , no. 2, pp. 463-486, 2011.

[28] S. L. Goldman, R. N. Nagel, and K. Preiss, "Agile Competitors and Virtual Organizations: Strategies for Enriching the Customer," Long Range Plann., vol. 29, p. 131, 1995. 
[29] R. A. Shafer, L. Dyer, and J. Kilty, "Crafting A Human Resource Strategy To Foster Organizational Agility: A Case Study Crafting A Human Resource Strategy To Foster Organizational Agility: A," 2000.

[30] R. Dove, Agile enterprise cornerstones: Knowledge, values and response ability, no. May 2005, pp. 1-11, 2006.

[31] Dove, R. Tools for analyzing and constructing agile capabilities, Bethlehem, PA: Agile Forum, January 1996

[32] H. Jorfi and G. Branch, "Surveying the Relationship between Organizational Innovation and Organizational Agility at Ramin Power Station of Ahwaz," vol. 2, no. 10, pp. 83-88, 2013.

[33] C.-T. Lin, H. Chiu, and Y.-H. Tseng, "Agility evaluation using fuzzy logic," Int. J. Prod. Econ., vol. 101, no. February 2016, pp. 353-368, 2006.

[34] M. Jackson and C. Johansson, "An agility analysis from a production system perspective," Integr. Manuf. Syst., vol. 14, no. 6, pp. 482-488, 2003.

[35] R. Imreh and M. Raisinghani, "Impact of Agile Software Development on Quality within Information Technology Organizations," J. Emerg. Trends Comput. Inf. Sci., vol. 2, no. 10, pp. $460-475,2011$.

[36] L. Dyer and J. Ericksen, "Dynamic Organizations: Achieving Marketplace Agility Through Workforce Scalability Dynamic Organizations : Achieving Marketplace Agility Through,” 2006.

[37] A. Gunasekaran and Y. Y. Yusuf, "Agile manufacturing: A taxonomy of strategic and technological imperatives," Int. J. Prod. Res., vol. 40, pp. 1357-1385, 2002.

[38] M. J.G., "Exploration and exploitation in organizational learning," Organ. Sci., vol. 2, no. May 2014, p. 71, 1991.

[39] CHANG, J., F. Business Process Management Systems. Strategy and implementation. New York: Auerbach Publications, 2006, ISBN: 978-0-8493-2310-2.

[40] Jackson M, Johansson C Agility Analysis from a Production System Perspective. Integrated Manufacturing Systems 14: 482-488 2003.

[41] Holsapple, Clyde W Understanding organizational agility: a workdesign perspective, International Command and Control Research and Technology Symposium, 2008.

[42] E. Overby, A. Bharadwaj and V. Sambamurthy, Enterprise agility and the enabling role of information technology", European Journal of Information Systems, 2006. 